\title{
Examining the relationship between learning capabilities and organizational performance: The mediating role of organizational innovativeness
}

\author{
Khawar Hussain ${ }^{1}$, Eta Wahab ${ }^{1}$, Ali Zeb ${ }^{1}$, Muhammad Asad Khan ${ }^{1}$, Mudaser Javaid ${ }^{1}$, Muhammad Ayaz Khan ${ }^{1}$, \\ ${ }^{1}$ Faculty of Technology Management and Business, Universiti Tun Hussein Onn Malaysia, Johor Malaysia
}

\begin{abstract}
This paper investigates the Organizational Learning Capabilities (OLC) affect Organizational innovativeness (OI) on organizational performance (OP). The mediating role of IO on relationship between OLC and OP was also been studied. Analysis is based on data collected from 200 respondents drawn from Pakistan's Telecom Sectors. Multiple regression analysis had been used to test the hypotheses. This study found that both OLC and OI have a positive impact towards OP. OI also mediates the relationship between OLC and OI. Key word: Organizational Learning Capabilities (OLC), Organizational Performance (OP), Organization Innovativeness (OI).
\end{abstract}

\section{INTRODUCTION}

\subsection{Background of study}

OLC has been believed by academics and practitioners as vital for associations generally due to the fast-changing environment. Firms that are able to discover stand a larger chance of detecting, replacing, and adapting on a vibrant nature [1]. Learning capability (LC) is an element of Organizational capabilities (OC) and an essential factor for OI [2]. The ancestor of the LC of the OC extends to use of how organization can grow new items with success of the OI (strategic, market, process, product and behavioral innovativeness) [3]. Innovativeness is believed as an individual and collective discovering procedure that inclines to find new methods of resolving problems [4]. Prior scrutiny suggests that OLC affects product innovation [5]. With the growing rate of rivalry, knowledge exploration and information support to develop the OLC for enhancing innovation and performance [6]. Akgun et al., [7] noted that OLC build up a hierarchical learning capacity, which shows the capacity of an organization to execute the suitable administration practices, method and structures that encourage and empower learning process, in addition, the OLC is essential subject for research scholar and managers [7]. Particularly, the role of the OLC is important for enhancing OI [4]. Further, Developing the LC supports to resolve the business issues, to face the competitor's challenges and to grant the survival and achievement of the organization into the future.

Moreover, the OP is enhanced by OLC and IO. While, the origins of discovering at the organizational level, OLC are mainly established on macro level constructs, such as supportive constructions, and routines that foster collective learning and a smaller amount of research theories have delineated organizational innovativeness as growing across sequential procedures that transpire at disparate levels of scrutiny [5]. They argued OLC as the adoption of a believed whether pertaining to a mechanism, arrangement, procedure, strategy, plan, product or ability that is new to the adopting association [7]. They think Innovativeness as transpiring in three different groups i.e. managerial skill development, new procedure and product [8]. The OLC have been subjected to the attention of scrutiny as it contributes to the survival and sustainability of an association and the OP, temporarily, has not been often times described and has been utilized differently according to the context, as well as being tough to delineate and compute [9].

Finally, this paper is concerned with the organizational learning capabilities toward organizational performance (financial and nonfinancial) in the service sector. Five facets of

* Corresponding author : khawarpm786@gmail.com 
Organizational Learning Capabilities have considered for research purpose, namely: Leadership Commitment \& Empowerment, shared vision and mission, dialogue, participative decision making, transfer of knowledge with the intervening impact of Organizational Innovativeness's three dimensions: Behavioral Innovativeness, Process Innovativeness and Strategic Innovativeness onto the association amid Organizational Learning Capabilities and Organizational Performance (financial and nonfinancial). Problem Statement: is pointed out Organizations are striving to sustain themselves in globalized and competitive environment. They are facing ambiguity, complexity and challengeable situations in business processes [10]. Due to intensive economic pressure and competitive environment organizations are facing problems and they are probing different ways to enhance their core competencies with a view to gain competitive advantage. Camison, and Lopez [8] explained that intensive competitive environment force organizations to keep themselves updated and learned about organizational environment in which they operate. This is an issue that how organizations can increase their intellectual assets and learning capabilities with a view to retain in competitive zone.

In addition to gap Analysis: The research explorations undertaken pertaining to Organizational Learning capabilities and innovativeness so far, largely encompass the manufacturing sectors while with very little focus onto the service-oriented sector and that also in the Asian and South Asian contexts. The meticulous review of the literature available onto the said spheres together with $[9,11,12,13]$ explorations who recommended that organizational innovativeness may further be assessed with Organizational learning capabilities (OLC) in relation to organizational performance, while Khalib et al., [11] recommended that five facets of OLC namely: (MC) Managerial Commitment, (EAO) experimentation and openness, (DG) Dialogue, (PDM) Participative Decision Making, and (KT) Knowledge Transfer may be tested in the context of service oriented firms, and behavioral, process and strategic innovativeness with regard to innovation in the artificial bodies. This research study will focus onto the service-oriented firms on account of them being an eschewed and overlooked area pertaining to learning and innovation research. The five aforementioned facets of Organizational Learning Capabilities as Independent Variable, Innovativeness with its three factors (Process, behavioral and strategic Innovation) as intervening variable and organizational performance as the outcome variable have been brought under this research exploration.
First, research objective, is to investigate the relationship between the OLC and OP, second is to assess the link between the OLC and OI, third is to examine the relationship between OI and OP and fourth is to analyze the intervening impact of OI on the relationship between OLC and OP. The current paper seeks to answer of its questions: Do OLC positively relate to OI? Do OLC relate to OP? Do OLC positively impact OP? Does OI mediate the relationship between OLC and OP?

Finally, the past studies that OLC influence on OI [2] and they determined that OLC affect OP. Rubera and Kirca, [4] explored that OI impact on OP. The contribution of present study is examined that OI mediates the relationship between OLC and OP. Significance of the study: according to dynamic rapid change in knowledge, OLC is a strategic tool in business management to enhance OI and OP for gaining competitive advantage; Learning practices are considered keystone to mitigate the uncertainties and to adopt the external changes in effective manners to gain \& sustain the competitive edge [6] [14]. These practices can be organized, analyzed, managed and improved with efficiency \& effectively to polish the management learning skills. Continues $\&$ effective learning leads to create an innovative culture which move the organizational performance curve in upward trend. Innovation can lead an organization towards growth and improvement in business processes which ultimately leads to get core competencies and competitive edge. Under study variables have significance importance to grow organizational performance [13].

\section{Literature Review}

\subsection{Organizational Learning Capability}

OLC can be delineated as the characteristics, traits, habits, dexterities and the agents pertaining management, association and the establishment as a whole that enable the discovering procedures of the association (e.g., producing, buying, disseminating and integrating information/ knowledge) or permits an association to discover [20]. Organizational discovering skill is concerning the skill of one association to apply the precise and appropriate association habits, its constructions, as well as the procedures that enhance, enable and enthuse discovering [15]. According to Argote [16], organizational discovering skill is the organizational and managerial agents that enable the organizational discovering procedure or permitting the association to learn. Salim, \& Sulaiman [17] added that the development of this exercise should consequence 
stronger discovering skill across the organization. The believed of organizational discovering skill gives significance of the enabling factors for organizational discovering or the organizational propensity to discover [18]. On the supplementary hand, Tohidi et al. [19] uttered that OLC are the organizational and managerial factors that give to the enhancement of organizational discovering procedure in organization. As per myriads of scrutiny explorations, OLC is believed as a multi-faceted concept. After going across the works, such conspicuous facets of OLC have been ascertained [8].

\subsection{Organizational Learning Capabilities and Performance}

This knowledge and vision have connection alongside non-financial and commercial presentation of organization. Benefits of discovering and vision association are alike for the area as well as confidential organizations. Furthermore, Camison and Lopez [8] explained that learning directions and innovative culture within the organization have positive and strong association with organization performance. These factors are behaving like cornerstone to improve the organizational performance. Organizational learning and innovativeness have positive link so there should be learning culture within the organization to enhance the innovative capabilities \& performance.

Learning practices within the organization can be considered as antecedent factor for organizational commitment, effectiveness and efficient performance. These learning practices have moderate positive relation with effectiveness and strong positive relation with organizational commitment [12]. Similarly Onag et al. [13] summed up that organizations having learning mechanism and showing progress in their learning processes can improve their performance but financial measures alone are not enough to judge the organizational performance. Employees' measures are effectively \& strongly related with learning capabilities. Khalib et al. [11] described that organizational learning has well-built, positive \& significant relationship with financial and non-financial measures and performance. As well organizations can build long term relations with employees, customers and suppliers with handsome financial position. Organization learning is considered a vital concept in strategic management due to its effectiveness. In present situation organizations should put organized efforts to gain the strategic learning. Organizations that will manage and develop the higher level learning will gain in terms of profitability and employees value addition relative to their rivals.

Organizational learning has vital role to enhance the organizational performance. Discovering has a momentous correlation alongside performance. Human resource hobbies alter the Discovering of organization. Due to globalization, new discovering necessities are believed vital for the improvement. Discovering habits are the path to accomplish the accomplishment, larger presentation and competitive advantage [9]. Thus H1: there is a relationship between OLC and OP.

\subsection{The Association between Organizational Learning Capability and Organizational Innovativeness}

OLC supports OI by rising employees' creativity and enhancing their knowledge. Vision allocating within organizations across contact and contact establishes appropriate nature for the collective power of organizational innovativeness [19]. In fact, an outstanding deal of scrutiny has believed new vision as the basis for change [21] understanding innovativeness as an individual and collective discovering procedure that aims to pursue new methods of resolving problems. Innovativeness seems to depend on the company's skill to discover, across that new vision is industrialized, distributed and used. Though, innovativeness can additionally be believed as a catalyst of new vision, as the extremely procedure of and the feedback from prosperous or ineffective aftermath can lead to a new vision of the marketplace or the product [10].

The innovativeness procedure implies enhancing and asking concerning the procedure itself and the possible innovativeness output, that way adaptive and generative discovering or single- and double-loop discovering [8]. One of the early periods in the innovativeness procedure is the creation of an believed or believed that needs hunting for opportunities, vision and brainstorming, that can be believed as a method of communal discovering [13], whereas disparate actors give, interrelate and in the end learn. In sum, change can enhance discovering inside associations [9]. Thus H2: There is a relationship between OLC and OI.

\subsection{Innovativeness and Performance}

Slater et al. [10] clarified that discovering orders and innovative sophistication inside the association have affirmative and forceful association alongside association performance. These factors are behaving 
like cornerstone to enhance the organizational performance. OI is considerably \& affirmatively associated alongside organizational performance. Innovativeness provides a competitive supremacy in the marketplace. In globalization scenario, competent and effectual use of discovering skills are believed vital basis to maximize the organizations' change presentation alongside a think to gain competitive advantage [11]. Thus H3: There is a relationship between OI and OP.

\subsection{The Intervening Role of organizational Innovativeness between the Relationship of Organizational Learning Capability and Performance}

The works indicate that company innovativeness enhances a firm's commercial performance. Specifically, company innovativeness supports the progress of a firm's core competencies and skills [5]. This method, the competencies a stable possesses and its skills, expertise, experience and the skill to deed enhance the firm's efficiency in noticing and using obtainable resources; these competencies additionally foster the progress of resolutions to company setbacks and arrest market-driven gains that undeviatingly elucidate into higher commercial presentation [7]. Furthermore, comprehensive facts in the works indicates that company innovativeness facilitates the capitalization of changes across lowered creation prices, reductions in transport period and increased operational flexibility [21]. This suggests that the connection amid OLC and commercial presentation can be clarified by incorporating the arbitrating act of innovativeness [9, 11]. Thus H4: OI mediate the relationship between OLC and OP.

\subsection{Theoretical Framework}

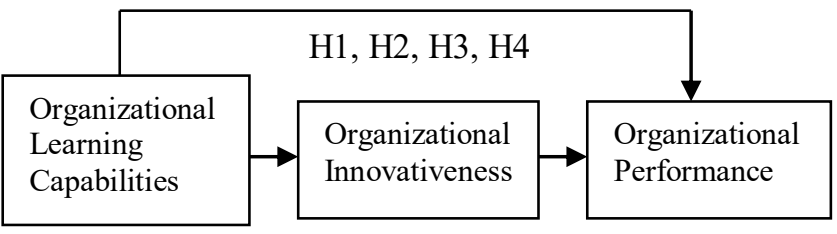

Fig.1. Theoretical Framework

\subsection{Research Hypotheses}

H1: There is a positive association between Organizational Learning Capability (OLC) and Organization Innovativeness (IO). H2: There is a positive relationship between Organization Innovativeness (IO) and Organization Performance (OP). H3: There is a positive association between Organization Learning Capability (OLC) and Organizational Performance (OP). H4: Organization Innovativeness (IO) positively mediates the association amid Organization Learning Capability (OLC) and Organization Performance (OP).

\section{Research Methodology}

An preliminary analysis of the literature discovered a lack of suitable items for measuring the defining constructs of OLC that are listed in Figure 1, The researchers chose to adopt and develop appropriate operationalizations to design an instrument that specifically and directly measures these constructs in order to ensure the reliability and validity of the measurement instrument process that we followed to develop and validate the instrument and summarizes the key techniques that we employed. To examine the validity and reliability of our measurement instrument for OLC and OI, we have used exploratory factor analysis.

\subsection{Research Design}

This is a causal, cross-sectional and quantitative study. In quantitative research design, an analytical and systematic approach has been used to analyze the data for information and to test the proposed hypotheses. Sample Selection and Strategy: 200 employees responded from 2000 employees Population In this study, the employees (Managers and Non-managers) of telecom industries were selected in Rawalpindi and Islamabad to take as population. Non probability convenience sampling method is the selected method for this research that helps gathering data from the people who are easily available. The questionnaire was filled by employees of all levels and, of different age groups and gender.

Unit of Analysis: The unit of analysis in this study is the employees functioning in telecom sector, and other small corporations). Unit of analysis is, individuals including all service providing managers and process owners, top management and administrative staff of telecom industries in Islamabad. 


\subsection{Construct development and instrument validation}

OLC includes five dimensions; (i.e. managerial commitment (04 items) and experimentation and openness (06 items), dialogue (06 items), participative decisions making (05 items) and knowledge transfer (05 items) [13], secondly, OI comprises three factors (i.e. process innovativeness (04 items) and behavioral innovativeness (04 items), and strategic innovativeness (04 items) [3] and thirdly, organization performance (i.e. financial (04 items) \& nonfinancial (12 items) [27] respectively, The questionnaire has total items 51 they were used five points Likert to examine the responses. The measurement scale ranged from one (strongly disagree) to five (strongly agree).

\subsection{Data Collection Methods for Pilot Testing}

It is self-administered survey. Questionnaires were circulated to employees functioning in different banking and telecom organization in Rawalpindi and Islamabad. 80 questionnaires distributed to different organization, 70 were returned and processed for pilot testing.

\subsection{Validity of the Instrument}

After getting the questionnaire approved by the subject experts it was administered to the sample of participants for pilot testing. The value of Cronbach Alpha should be greater than 0.70 [22, 23]. The internal consistency i.e. the reliability of the items which was greater than point six $(0.70)$ assured that the instrument was reliable and researcher could proceed with it. All of the utilized constructs are well supported in the prior literature. Specifically, the face validity was conducted by professional experts. The pilot testing is conducted on software of SPSS 21 using Cronbach alpha [26].

Table 1. Reliability of items of pilot study

\begin{tabular}{|c|c|c|}
\hline Variable(s) & $\begin{array}{c}\text { No. of } \\
\text { items }\end{array}$ & $\begin{array}{c}\text { Cronbach's } \\
\text { Alpha }\end{array}$ \\
\hline OLC & 23 & .865 \\
\hline OI & 12 & .727 \\
\hline OP & 16 & .762 \\
\hline
\end{tabular}

The instrument was pilot tested employing a example of 70 workers from the target population. The result of pilot study conferred seized adequacy [22]. The Cornbach's alpha of all variables ranged from .727 to 0.865 [26].

\subsection{Demographics analysis}

The summary of the demographics is provided in the details of the respondents. The age of the participants are divided into seven groups in which $14.5 \%$ participants were of age $20-25$ while $35.5 \%$ lies between the ages of $26-30,21.0 \%$ were of $31-35$, $17.5 \%$ were from $36-40,9 \%$ were from $41-45,2.5 \%$ were in range of $46-45$ and only $0.0 \%$ were of age 51 and above. Gender group is divided in two parts Male and Female, Male respondents were $70 \%$ while only $30 \%$ were females. Most of the respondent $80 \%$ were belonging to non-manager grade while only $20 \%$ respondents were belonging to manager grade. $35 \%$ respondents had bachelors' degree, $50.5 \%$ were masters, and only $14.5 \%$ was having MS/M.Phil degree.

\subsection{Descriptive analysis}

The results indicate general agreement of the respondent to the study variables which are organizational learning capabilities, organizational innovation and organizational performance. The mean values ranged from low 3.2609 to highest 3.2811. It shows the results of OLC $(\mathrm{M}=3.2811$, $\mathrm{S} . \mathrm{D}=.67165$, Skewness $=-.606$, Kurtosis $=-.628)$, OI $(\mathrm{M}=3.2988$, S.D $=.66914$, Skewness $=-.666$, Kurtosis= -.2324), OP $(\mathrm{M}=3.2609$, S.D $=.67827$, Skewness $=-.482$, Kurtosis $=-.723)$. The result of descriptive statistics i.e. Means, S.D, Skewness, further, Skewness results demonstrate OLC to OP to have negative values those are very flat and have a greater number of larger values and Kurtosis show the conformity of the participant's thoughts towards all variables. Kurtosis determined flatness or peaked of a distribution, here, kurtosis results expose negative values of all variables those are vary peaked than normal and data is good for using psychometric. To evaluate the normality of the data, Skewness and Kurtosis were utilized. Literature illustrates that the value of Skewness should be between +1 to -1 to prove the normality of the data [25]. Descriptive values are within the range which proves the normality of the data. Kurtosis is also a measure of the normality of data. The ideal value of kurtosis is 3 [22]. 


\subsection{Reliability Analysis}

First, the instrument was adapted, and to check the internal consistency of the items, the following table 2 shows the results.

Table 2. Internal consistency (reliability) of important variables $(\mathrm{N}=200)$

\begin{tabular}{|c|c|c|}
\hline Variables & $\begin{array}{c}\text { No of } \\
\text { items }\end{array}$ & $\begin{array}{c}\text { Cronbach's } \\
\text { Alphas }\end{array}$ \\
\hline OLC & 23 & .834 \\
\hline OI & 12 & .734 \\
\hline OP & 16 & .838 \\
\hline Total & 51 & \\
\hline
\end{tabular}

The value of Cronbach Alpha should be greater than 0.70 [23]. The results demonstrate that the value of Cronbach Alpha of all the variables is greater than 0.70 [24].

\subsection{Correlation Analysis}

Table 3. Correlations

\begin{tabular}{|c|c|c|c|}
\hline & OLC & OI & OP \\
\hline OLC & 1 & & \\
\hline OI & $.744^{* *}$ & 1 & \\
\hline OP & $.877^{* *}$ & $.475^{* *}$ & 1 \\
\hline \multirow{2}{|c|}{ **. Correlation is significant at the 0.01 level (2-tailed). } \\
\hline
\end{tabular}

The Table 3 explains the correlation among all the constructs that are used in theoretical model. From the table 3 , it has been concluded that OLC have the highest positive correlation $(0.877)$ with the OP. The value of correlation ( 0.744 and .475$)$ indicates that OI has positive and statistically significant association with OLC, and OP. Furthermore, all other variables' correlations show a positive and statistically significant relationship between the variables. Moreover, all the variables results of correlation are significant at the 0.01 level [25] [26].

\section{Measurement and Model evaluation}

\subsection{Multiple Regression Analysis}

Hayes [24] explained that the mediation models can be explained in model templates. Therefore, researcher has tested mediation on Process Model 4. PROCESS Models of Hayes [24] has been used in
SPSS 21 to test the direct and indirect effect of predictor variables on outcome variables. Regression analysis also shows the fitness of model with the value of $\mathrm{R}$ square depicts the explanatory power of the model. The study used one independent variable, one dependent and mediation variables.

Table 4. Direct and indirect relationship with Mediation Analysis using Hayes [24] $(\mathrm{N}=200)$

\begin{tabular}{clccc}
\hline Steps & Test & B & T & $\begin{array}{c}\text { R } \\
\text { square }\end{array}$ \\
\hline Direct & OLC $\longrightarrow$ OO & .95 & 3.08 & .82 \\
Media & IO $\longrightarrow$ OP \\
tion & OLC $\longrightarrow$ OP \\
Direct & OLC $\longrightarrow$ OP & & \\
.57 & 5.85 & .804 \\
.46 & 4.45 & .80 \\
.46 & 4.45 & .80
\end{tabular}

In this case, while the independent variable (OLC) was a significant predictor for the dependent (OP) and the mediator variables (IO), it is no longer significant in the presence of the mediator variable; confirming the mediation effect. A measure for the indirect effect of $\mathrm{X}$ on $\mathrm{Y}$ is also presented after the regression models. In this case the effect size was .5740 , with a $95 \%$ confidence interval which did not include zero; that is to say the effect was significantly greater that zero at $\alpha=.05$.

\subsection{Findings}

The above table 4 shows that value of $\mathrm{R}$ square is 0.82 . This shows that $82 \%$ variation in the IO is being explained by OLC. P-value is (.000) which means this relationship is also highly significant. OLC is regressed on the mediating variable which is IO was also significant $(\beta=.9569$, $\mathrm{t}$-value $=3.080, \mathrm{p}$ $=<.000$ ). It shows that OLC have a significant effect on the IO.

First, in step 2 of the mediation process showed that the mediator (IO (MV)), controlling for OLC, thus, beta value $\beta=.574$, $\mathrm{t}$-value $=5.859$ is significant at $\mathrm{p}$-value $=.000$. The $\mathrm{R}$ square result $\left(R^{2}=0.804\right)$ divulge that the IO has accounted for $80.4 \%$ variation in OP. Thus IO relationship with OP is accepted and positive. Second, controlling for MV (IO), OLC was significant predictor of OP, $\beta=.4669$, $\mathrm{t}$-value $=4.452, \mathrm{p}$-value $=.000$. The $\mathrm{R}$ square result 0.80 confirms the models fitness. Hence H1, H2, H3, and $\mathrm{H} 4$ are both supported. From the above results it can be safely concluded that IO partially mediates the relation between OLC and OP.

OLC as a predictor has positive impact on organizational performance as outcome, therefore, 
while using SPSS 21 [24] Model 21, we regressed OLC on OP, findings shows (see table 8) that value of $\mathrm{R}$ square is 0.80 , this indicate that there is $80 \%$ variation in the OP is explained by the OLC and beta coefficient was $\beta=.4669$, $\mathrm{t}$-value $=4.452$, $\mathrm{p}$-value $=$ $<.000$. It shows that direct relationship is positive and significant at $(p<.01)$ to indicate acceptance of hypothesis. So the result explains that the hypotheses are accepted and indicates positive impact on improving organizational performance.

\section{Implications, Recommendations and Conclusion}

\subsection{Theoretical implication}

The current paper is found from past studies that OLC influence on OI [2] and they determined that OLC affect OP. Rubera and Kirca [4] explored that OI impact on OP. The present study is examined that OI mediates the relationship between OLC and OP. Argote [16] counseled that novel methods of coordinating work, adjustments in association actions or company strategies, enhanced forms of association or new configurations of organizational constructions are central in enabling company accomplishment and increased financial performance. OLC affect OP positively. OLC impact on OI positively. According to Tuksinnimit et al. [9] whole research work is determined that OLC influence on OP by mediating role of IO that enhance performance financially and nonfinancially.

\subsection{Managerial Implication}

Managers should pay attention on OLC for developing skill, knowledge, increasing experience for decision making and performance [7]. Organizations can build long term relation with their employees, customers, suppliers and handsome position for enhancing innovation [2]. In present situation organizations should organized efforts to gain the strategic learning. Further, Organizations manage and develop the higher level learning, to gain innovative ways, employees' value and profitability [19].

\subsection{Research Limitations}

In Pakistan's organizational context in which examined the effect of organizational learning capabilities (i.e. covered managerial commitment, experimentation and openness, dialogue, participative decision making and knowledge transfer) on organizational innovativeness (i.e. covered behavioral innovativeness, process innovativeness and strategic innovativeness and organizational performance (i.e. covered financial and non financial). Further, positive relationship was tested between OLC, OI and OP. Moreover, it was conducted in Islamabad's Telecom organizations. Small sample size was taken and convenient sampling was used.

\subsection{Future Recommendations}

Further, demission of OLC, IO and OP may be examined empirically. In addition, sample size can be increased base on demographically and population. Moreover, innovative culture might be used as moderator. Transformational leadership and authentic leaderships are tested as independent variables. Those are most important for enhancing the OLC, OI and OP. Finally, developing the innovative environment in an organization, it might be conducted in different organization e.g. manufacturing, services, food organizations.

\subsection{Conclusion}

This research proves that organizational learning capabilities have strong effect on organizational innovativeness and organizational performance [27]. Further, in the domain of organizational learning capabilities (Experimentation and openness, participative decision making, Knowledge transferring and managerial commitment) within organizations through behavioral, process and strategic interaction are established appropriate environment for organizational innovativeness. Finally, firms can implement on organizational learning capabilities approach make use for its developing new management technique, process, innovative products and enhancing performance.

\section{References}

1. Cheng, C., Lai, M. \& Wu, W. (2010), "Exploring the impact of innovation strategy on R\&D employees' job satisfaction: a mathematical model and empirical research", Technovation, Vol. 30 Nos 7/8, pp. 459-70.

2. Alegre, J., \& Chiva, R. (2013). Linking entrepreneurial orientation and firm performance: the role of organizational learning capability and innovation performance. Journal of Small Business Management, 51(4), 491-507. 
3. Wang, C. L., \& Ahmed, P. K. (2004). The development and validation of the organizational innovativeness construct using confirmatory factor analysis. European journal of innovation management, 7(4), 303-313.

4. Rubera, G., \& Kirca, A. H. (2012). Firm innovativeness and its performance outcomes: A meta-analytic review and theoretical integration. Journal of Marketing, 76(3), 130147.

5. Cropley, D. H., \& Cropley, A. J. (2012). A psychological taxonomy of organizational innovation: Resolving the paradoxes. Creativity Research Journal, 24, 29-40.

6. DiBella, A. J., Nevis, E. C., \& Gould, J. M. (1996). Understanding organizational learning capability. Journal of management studies, 33(3), 361-379.

7. Akgun, A.E., Ince, H., İmamoglu, S.Z., Keskin, H. and Kocoglu, İ. (2013), The mediator role of learning and business innovativeness between total quality management and financial performance. International Journal of Production Research, Vol.52, No. 3, 888-901.

8. Camison, C., \& Villar-Lopez, A. (2014). Organizational innovation as an enabler of technological innovation capabilities and firm performance. Journal of Business Research, 67(1), 2891-2902.

9. Tuksinnimit, N., Durongwatana, S., \& Vadhanasindhu, P. (2015). The Factors Affecting Organizational Innovativeness. Journal of Management Research, 7(2), 561-573.

10. Slater, S. F., Mohr, J. J., \& Sengupta, S. (2014). Radical product innovation capability: Literature review, synthesis, and illustrative research propositions. Journal of Product Innovation Management, 31(3), 552-566.

11. Khalib, L. H., Kassim, N. A., Ghazali, F. I., Jaafar, N., \& Idris, A. (2015). Organizational Learning Capabilities (OLC) toward Job Satisfaction: A Conceptual Framework.

12. Hogan, S. J., \& Coote, L. V. (2014). Organizational culture, innovation, and performance: A test of Schein's model. Journal of Business Research, 67(8), 1609-1621.

13. Onag, A. O., Tepeci, M., \& Başalp, A. A. (2014). Organizational Learning Capability and its Impact on Firm Innovativeness. ProcediaSocial and Behavioral Sciences, 150, 708-717.

14. Menold, M. J., Jablokow, K., Purzer, S., Ferguson, D. M., \& Ohland, M. W. (2014). A critical review of measures of innovativeness. age, 24, 1.
15. Gunsel A., Siachou E. and Acar A. Z., (2011), Knowledge management and learning capability to enhance organizational innovativeness, Procedia Social and Behavioral Sciences, 24, pp.880-888.

16. Argote, L. (2011). 'Organizational learning research: past, present and future', Management Learning, 42, pp. 439-446. Armstrong, J. S. and T. S. Overton (1977). 'Estimating nonresponse bias in mail surveys', Journal of Marketing Research, 14, pp. 396-402.

17. Salim, I. M. and M. Sulaiman (2011). 'Organizational learning, innovation and performance: a study of Malaysian small and medium sized enterprises', International Journal of Business and Management, 6, pp. 118-126.

18. Bess, K.D.,Perkins, D.D., \& McCown, D.L. (2011), Testing a mesure of organizational learning capacity and readiness for transformational change in human services. Journal of Prevention and Intervention in the Community, Vol.39, pp.35-49.

19. Tohidi H., Seyedaliakbar S. M., Mandegari M., (2012), Organizational learning measurement and the effect on firm innovation, Journal of Enterprise Information Management, Vol. 25 Iss: 3 pp. $219-245$.

20. Campbell, C., Silver, I., Sherbino, J., Ten Cate, O. and Holmboe, E. (2010), "Competency-based continuing professional development", Medical Teacher, Vol. 32 No. 8, pp. 657-62.

21. Real, J. C., Roldan, J. L., \& Leal, A. (2014). From entrepreneurial orientation and learning orientation to business performance: analysing the mediating role of organizational learning and the moderating effects of organizational size. British Journal of Management, 25(2), 186-208.

22. Sekaran, U. (2003). Research methods for business. Hoboken.

23. Nunnally, J. C. (1979). Citation classicpsychometric theory. Current Contents/Social \& Behavioral Sciences, (22), 12-12.

24. Hayes, A. F. (2013). Introduction to mediation, moderation, and conditional process analysis: A regression-based approach. Guilford Press.

25. Cooper, D. R., \& Schindler, P. S. (2008). International Edition: Business Research Methods.

26. Straub, D. W. (1989). Validating instruments in MIS research. MIS quarterly, 147-169.

27. Damanpour, F.; Walker, R. M.; Combinative, C. N. A. 2009. Effects of innovation types and organizational performance: a longitudinal study of service organizations, Journal of Management Studies 46(4): 650-675. 